\title{
Finite Element Simulation of the Vibration Provided by Sandwich Rigid Panel with a Resilient Material In Between under Heavyweight Impact
}

\author{
Shun-Fa Hwang, ${ }^{1}$ Chao-Wen Chen, ${ }^{1}$ Sung-Chin Chung, ${ }^{2}$ and Yaw-Shyan Tsay ${ }^{2}$ \\ ${ }^{1}$ Department of Mechanical Engineering, National Yunlin University of Science and Technology, 123 University Road, Section 3, \\ Douliu, Yunlin 64002, Taiwan \\ ${ }^{2}$ Department of Creative Design, National Yunlin University of Science and Technology, 123 University Road, Section 3 , \\ Douliu, Yunlin 64002, Taiwan
}

Correspondence should be addressed to Shun-Fa Hwang; hwangsf@yuntech.edu.tw

Received 26 February 2014; Revised 19 May 2014; Accepted 20 May 2014; Published 23 June 2014

Academic Editor: Mohammad Elahinia

Copyright (c) 2014 Shun-Fa Hwang et al. This is an open access article distributed under the Creative Commons Attribution License, which permits unrestricted use, distribution, and reproduction in any medium, provided the original work is properly cited.

\begin{abstract}
The purpose of the present work is to use an explicit finite element code to model the impact behavior of a heavyweight impact source like rubber ball and to predict the floor impact vibration of resilient materials, which are used in the floor coverings construction for sound insulation. To simulate the impact force of rubber balls, the hyperviscoelastic rubber model is applied. Then, this rubber model is used in the simulation for the impact vibration of resilient materials. The results indicate that the hyperviscoelastic rubber model could precisely simulate the impact force of rubber balls, as its two parameters are properly chosen according to the desired impact force. Also, the present model could capture the impact and vibration behavior of the considered materials and reasonably evaluate the insulation effect of resilient materials.
\end{abstract}

\section{Introduction}

Due to the demand in the living quality, the sound environment needs to be further improved to meet this requirement. One type of environment noise is the floor impact sound, which may come from walking, furniture movement, object falling, or children jumping. This type of noise may cause the dispute between habitants of adjacent floors, especially in congregate housing. Therefore, reducing this type of noise has been the target of current building construction. Since the main structure of a building is difficult to change just for the reason of floor impact noise, floor coverings construction may be an effective and cheap method [1] to achieve this goal.

Floor impact sound is dependent on the characteristics of impact source, the vibration properties of the floors, and the sound emission. Ver [2] obtained a complete description of the force spectrum and impact level provided by tapping machine on hard surfaces. Cremer et al. [3] derived an impact source spectrum caused by tapping machine acting on homogeneous floor of high impedance. Shi et al. [4] experimentally concluded that a sand ball drop as an impact source provides a better representation of actual human footfall on wood joist floors than the standard tapping machine. To measure impact sound through lightweight walls in a laboratory, Huang et al. [5] recommended a steel ball of $50 \mathrm{~mm}$ in diameter as a hard impactor and a silicon ball of $100 \mathrm{~mm}$ in diameter as a soft one. Jeon and Sato [6] conducted objective and subjective evaluations of heavyweight floor impact sounds generated by a bang machine and an impact ball. Chung et al. [7] compared the automobile tire and rubber ball and verified the applicability of rubber ball as the standard heavyweight impact source. Jeon et al. [8] showed that the noise from the impact ball is similar to the noise of children running and jumping and found that the noise level of an impact ball is slightly higher than that of a bang machine, even though the impact ball has a lower impact force. Park et al. [9] predicted 
the impact force from a bang machine and an impact ball by using the measured modal properties and compared it to the measured excitation force.

To improve the vibration properties of the floors, the common way was to use floor coverings [10] or chipboard floating floor [11]. Ver [2] considered the improvement in insulation provided by the use of elastic surface layers or by floating floors with high-impedance surfaces. Tadeu et al. [12] proposed an analytical model to examine the impact sound insulation by a single panel and a floating layer system. Chiang et al. [13] revealed that the sound insulation was about 19-21 dB by the use of ceiling materials with different sound insulation coefficients, and it was about $9-11 \mathrm{~dB}$ by the change of the thickness of the ceiling airspace. Kuo [14] executed experimental investigation on floor impact sound insulation with various floor coverings, which were the combination of common coverings materials and damping materials, in a full-scale building. Rushforth et al. [15] experimentally compared the impact sound insulation performance of a range of materials made from recycled carpet tiles with some commercially available acoustic underlays. Kim et al. [16] experimentally investigated 51 resilient materials and concluded that as the dynamic stiffness of resilient materials decreases, the heavyweight impact sound level also decreases.

To understand the mechanism of floor impact sound, it is popular to simulate the floor impact behavior, especially by numerical methods. Neves E Sousa and Gibbs [17] developed an analytical model to investigate the effect of homogeneous base plates with homogenous floating floors on impact sound transmission at low frequencies. Finite element method was used to discuss the sound insulation effects of well-mixed ceiling [14], to simulate the floor impact sound of composite steel deck floors [11] and to analyze the effects of panel thickness and panel size on the impact sound insulation [18]. It was also applied to simulate double rooms with a light gauge frame partition to discuss the effects of the thickness of the light gauge frame partition, the volume of the double room, and the absorption coefficient of the interior decoration materials [19].

Since actual field measurements are time-consuming and need high costs, finite element simulation with better operation speed and low cost is a worth alternative for evaluating the creation and propagation mechanism of floor impact sound. From the above reviewed literature, the current finite element simulation for floor impact sound always focuses on the lightweight impact source from tapping machine, because the simulation is under the implicit mode that is easy to apply. However, to simulate the impact conditions of heavyweight impact source like the rubber ball, explicit finite element analysis is required, and this approach is seldom found in the literature. Before the sound insulation of floor coverings could be precisely simulated, it may be necessary to just focus on their vibration reduction. Therefore, the purpose of the present work is to use an explicit finite element code, for example, LS-DYNA, to model the impact behavior of the rubber ball and to predict the floor impact vibration of resilient materials. To simulate the impact force of rubber balls, the hyperviscoelastic rubber model will be applied. In addition, some parameter values in this model will be determined by
TABLE 1: The specific of standard heavy impact source of rubber ball [20].

\begin{tabular}{ll}
\hline Item & Value \\
\hline Mass & $2.5 \pm 0.1 \mathrm{~kg}$ \\
Shape & Hollow sphere \\
Diameter & $180 \mathrm{~mm}$ \\
Thickness & $30 \mathrm{~mm}$ \\
Restitution coefficient & $0.8 \pm 0.1$ \\
Shore A hardness & $40 \pm 5$ \\
Drop height & $1 \mathrm{~m}$ \\
Maximum impact force & $\sim 1500 \mathrm{~N}$ \\
Impact duration & $20 \pm 2 \mathrm{~ms}$ \\
\hline
\end{tabular}

TABLE 2: The calculated values of the waveform of the impact force.

\begin{tabular}{ll}
\hline Item & Value \\
\hline Force integration $(Y)$ & $19.92 \mathrm{~N} \cdot \mathrm{s}$ \\
Maximum impact force $\left(F_{\max }\right)$ & $1563.83 \mathrm{~N}$ \\
Average impact force $\left(F_{\text {avg }}\right)$ & $996.08 \mathrm{~N}$ \\
Velocity at impact $(V)$ & $4.427 \mathrm{~m} / \mathrm{s}$ \\
Average acceleration $\left(A_{\text {avg }}\right)$ & $398.43 \mathrm{~m} / \mathrm{s}^{2}$ \\
\hline
\end{tabular}

trial and error to create the standard heavyweight impact force. Then this impact force will be applied to the tested panel that may include resilient materials, and the effects of resilient materials on vibration reduction will be evaluated. As this impact simulation model has been established, it could be used to further evaluate the sound insulation of floor coverings in the future.

\section{Properties of Impact Force}

To simulate the sound of humans walking and running, the available heavyweight floor impact sources include bang machine, tapping machine, automobile tire, rubber ball, and sand ball. Recently, the rubber ball, as shown in Figure 1, is popular and standardized. The standard rubber ball [20] is a hollow sphere with the diameter of $180 \mathrm{~mm}$, thickness of $30 \mathrm{~mm}$, and mass of $2.5 \pm 0.1 \mathrm{~kg}$, as listed in Table 1 . Before it hits the floor, the rubber ball falls from $1 \mathrm{~m}$ height. The maximum impact force is about $1500 \mathrm{~N}$, and the impact duration is $20 \pm 2 \mathrm{~ms}$. One possible waveform of this impact force [20] is illustrated in Figure 2. Some calculated values from Figure 2 are listed in Table 2. The force integration represents the integration of the impact force with respect to time, and its value is about $19.92 \mathrm{~N} \cdot \mathrm{s}$.

\section{Experiments}

The impact vibration measurement was conducted in a fullscale building with a small size specimen according to ISO 140-11 [21], and its schematic diagram is shown in Figure 3. The point $\mathrm{A}$ is $100 \mathrm{~mm}$ away from the two adjacent sides and on the top surface of the solid wood. The dimensions of solid wood, plywood, resilient materials, and reinforced concrete floor (RC floor) are listed in Table 3. The rubber ball 


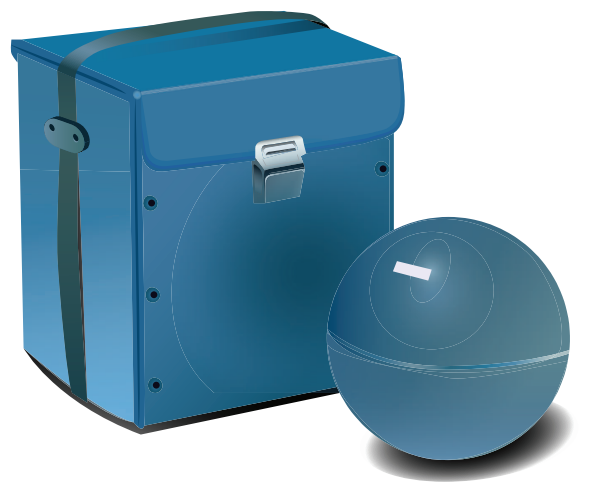

FIGURE 1: Rubber ball for heavyweight impact test.

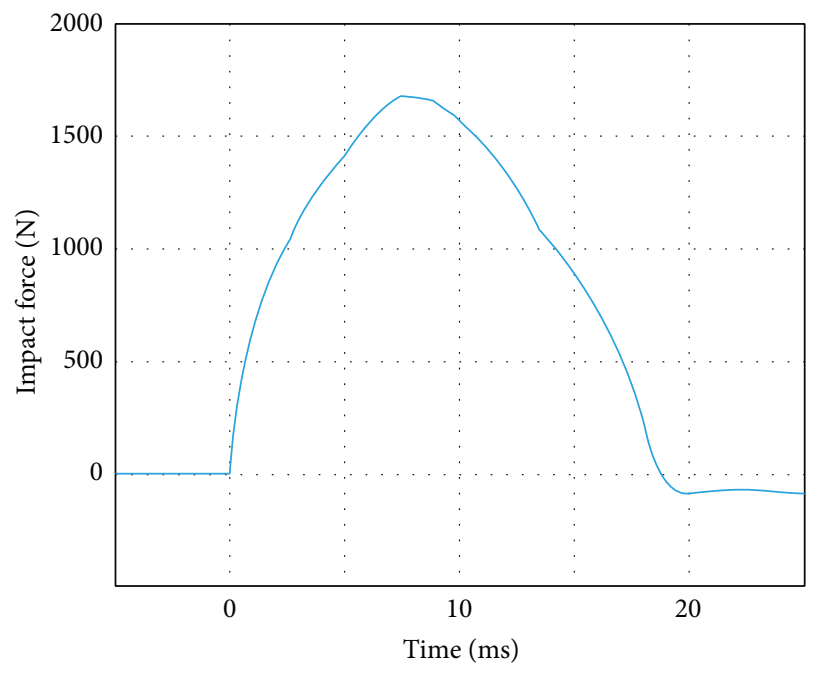

FIGURE 2: Waveform of impact force of rubber ball [20].

was released free from the height of $1 \mathrm{~m}$ and hit the tested panel after being released. The tested panel consisted of solid wood plate and plywood plate, if the resilient materials were not included. When the resilient material was added, one layer of resilient materials was put between the plywood and the RC floor as shown in Figure 3. The layers of solid wood and plywood were glued together during measurement. The acceleration measured at point $\mathrm{A}$ by an accelerometer $\mathrm{PCB}$ 353B14 was transferred to HP 35670A signal analyzer and processed by a personal computer. When only the impact force of the rubber ball was concerned, the impact testing was executed without the tested panel. That means the rubber ball directly hit the RC floor.

To obtain the stress-strain relation of resilient materials for inputting in the simulation, compression tests were executed on a HT9102 materials testing machine. The crosshead rate was set to be $16 \mathrm{~mm} / \mathrm{min}$ due to the limitation of the testing machine and the specimen thickness. Three layers of the same resilient material were compiled as a specimen with the dimensions of $35 \times 30 \times 30 \mathrm{~mm}$ for ethylene vinyl acetate (EVA) and $35 \times 30 \times 39$ for nitrile butadiene rubber (NBR). The test was stopped manually as the specimen was difficult to be further compressed. The resilient materials considered in this work belong to foam materials. EVA is the copolymer of ethylene and vinyl acetate and has similar softness and flexibility to elastomeric materials. Its features are in shockproof, crash, and thermal insulation. Since it has little or no odor, it is competitive with rubber and vinyl products in many applications. EVAs 25,35 , and 55 were three types of EVA used in this work, and the number indicated the degree of Shore A hardness. NBR is a synthetic rubber copolymer of acrylonitrile (ACN) and butadiene. It is generally resistant to oil, fuel, and other chemicals. Its resilience makes NBR a useful material for floor mats. NBR JS-607S used as shock absorption foam was chosen in this work, and its Shore A hardness was 18. To be consistent with the number of EVAs, NBR JS-607S is denoted as NBR 18 in this work because of its Shore A hardness.

\section{Impact Simulation}

4.1. Simulation Model. To simulate the impact vibration of the rubber ball on the floor, the commercial explicit finite element software, LS-DYNA, was selected. The 8-node brick element, Solid 164, was chosen to mesh all materials including the rubber ball, solid wood, plywood, resilient materials, and the RC floor. The dimensions of the rubber ball with the density of $1163 \mathrm{~kg} / \mathrm{m}^{3}$ are listed in Table 1 . The dimensions and mechanical properties of the other materials are shown in Table 3. The solid wood, plywood, and RC floor were treated as a linear isotropic material, while the resilient materials were treated as foam materials with the model described in Section 4.3. Since the rubber ball would impact the solid wood, automatic surface to surface contact was set between their surfaces. In the simulation, the solid wood and plywood were glued together as the real case. Since the three layers of plywood, resilient material, and RC floor were just put together, their interfaces were treated as tied surface to surface contact that was allowed to have node mismatch between them. One example of the finite element mesh of the rubber ball and tested panel on the RC floor is shown in Figure 4. As for the boundary conditions, the four sides of the RC floor were set to be fixed. To save the simulation time, the rubber ball was released at the height of $0.002 \mathrm{~m}$ from the surface of the RC floor with the velocity of $4.425 \mathrm{~m} / \mathrm{s}$, and the gravity was enforced along the vertical direction as shown in Figure 3 . The total simulation time was $23 \mathrm{~ms}$, and the time step was $0.1 \mathrm{~ms}$.

4.2. Model of Rubber Balls. Rubber is generally considered to be nearly incompressible because the bulk modulus greatly exceeds the shear modulus. Kinematic hardening plastic material model, Mooney-Rivlin rubber model, and hyperviscoelastic rubber model are three popular material models for rubber [22]. Among them, the hyperviscoelastic rubber model was verified to be suitable to model the rubber ball during impact conditions [23]. This material model could be considered as the combination of superelasticity 
TABLE 3: Material models and dimensions of the tested panel and RC floor.

\begin{tabular}{lcccccc}
\hline Material & Dimension $(\mathrm{mm})$ & Material model & Density $\left(\mathrm{kg} / \mathrm{m}^{3}\right)$ & Young' modulus $(\mathrm{MPa})$ & Poisson's ratio & Damping coefficient \\
\hline Solid wood & $595 \times 590 \times 18$ & Isotropic & 600 & 6000 & 0.305 & 0.3 \\
Plywood & $595 \times 590 \times 8$ & Isotropic & 900 & 8000 & 0.419 & 0.5 \\
NBR 18 & $595 \times 590 \times 13$ & Foam & 83 & 0.615 & 0.5 \\
EVA 25 & $595 \times 590 \times 10$ & Foam & 70 & 7.41 & 0.5 \\
EVA 35 & $595 \times 590 \times 10$ & Foam & Foam & 130 & 2.91 & 0.5 \\
EVA 55 & $595 \times 590 \times 10$ & Isotropic & 2400 & 210000 & 0.17 \\
RC floor & $7000 \times 3400 \times 160$ & &
\end{tabular}

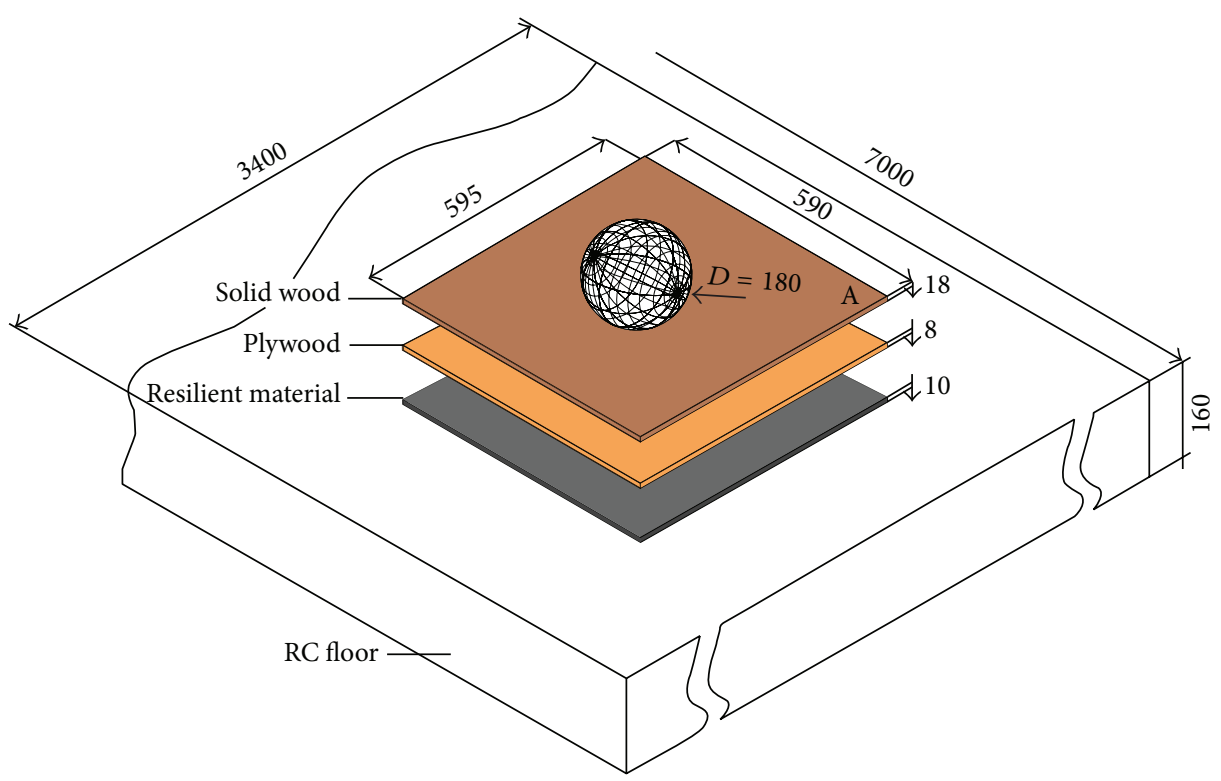

FIGURE 3: Schematic diagram for impact vibration measurement.

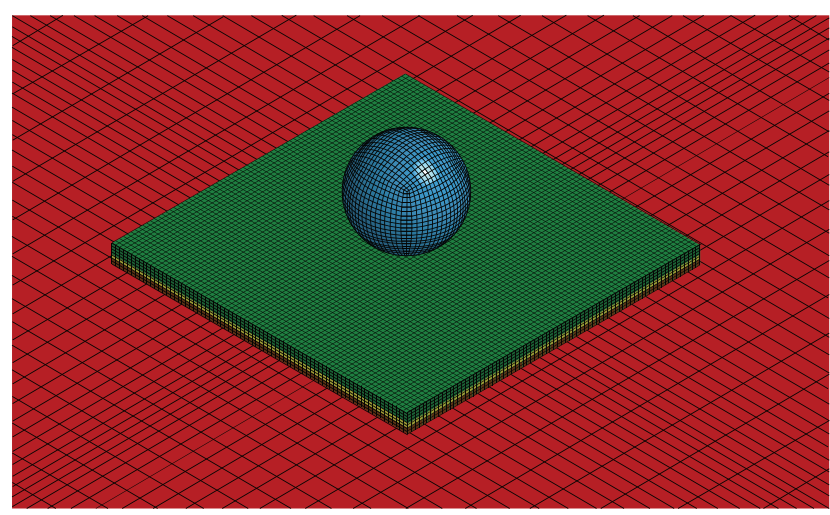

FIGURE 4: Finite element mesh for rubber ball and tested panel on the RC floor.

and viscoelasticity with a hydrostatic work term $W_{H}(J)$. The general form of the strain energy density function of this model is expressed as

$$
W=\sum_{p, q=0}^{n} C_{p q}\left(J_{1}-3\right)^{P}\left(J_{2}-3\right)^{q}+W_{H}(J)
$$

where the relative volume $J$ is defined as

$$
J=\lambda_{1}^{2} \lambda_{2}^{2} \lambda_{3}^{2}=\frac{V}{V_{0}}
$$

To prevent volumetric work from contributing to the hydrostatic work, the first and second modified invariants are defined as

$$
\begin{aligned}
& J_{1}=I_{1} I_{3}^{-1 / 3}, \\
& J_{2}=I_{2} I_{3}^{-1 / 3},
\end{aligned}
$$

where the three invariants of Cauchy-Green tensor are defined as

$$
\begin{aligned}
& I_{1}=\lambda_{1}^{2}+\lambda_{2}^{2}+\lambda_{3}^{2}, \\
& I_{2}=\lambda_{1}^{2} \lambda_{2}^{2}+\lambda_{2}^{2} \lambda_{3}^{2}+\lambda_{3}^{2} \lambda_{1}^{2}, \\
& I_{3}=\lambda_{1}^{2} \lambda_{2}^{2} \lambda_{3}^{2} .
\end{aligned}
$$

The principal stretch ratio in each direction is given by

$$
\lambda_{i}=\frac{L_{i}+\Delta L_{i}}{L_{i}}
$$


with $L_{i}$ being the initial length along $i$ direction and $\Delta L_{i}$ being the corresponding length change.

If only $n=1$ is selected in the strain energy density function and the hydrostatic term is not included, one can obtain the simplified strain energy density function as

$$
W=A\left(J_{1}-3\right)+B\left(J_{2}-3\right)
$$

The constants $C_{01}$ and $C_{10}$ have been replaced by $A$ and $B$, respectively. During the simulation, the two parameters $A$ and $B$ in the hyperviscoelastic rubber model will be varied according to Shore A hardness. The corresponding values between Shore A hardness, Young's modulus, shear modulus, parameter $A$, and parameter $B$ for rubber materials are shown in Table 4 [24].

4.3. Model of Resilient Materials. Since the resilient materials are highly compressible low density foams, Material Type 57 in LS-DYNA, whose main applications are for seat cushions and padding, was chosen in this work. In this model, tabulated data were input for the loading curve where the nominal stresses were defined as a function of the elongations $\varepsilon_{i}$. The elongations are defined in terms of the principal stretches $\lambda_{i}$ as

$$
\varepsilon_{i}=\lambda_{i}-1
$$

After obtaining the principal stretches and the elongations, the corresponding values of the nominal stress $\tau_{i}$ are interpolated, if the elongations are compressive. As the elongations are tensile, the nominal stresses are given by

$$
\tau_{i}=E \varepsilon_{i} .
$$

The Cauchy stresses in the principal system become

$$
\sigma_{i}=\frac{\tau_{i}}{\lambda_{j} \lambda_{k}}
$$

The stresses can now be transformed back into the global system for the nodal force calculations. Also, in this model the hysteresis effect and the strain rate effect were not considered. The viscous coefficient to model damping effects was assigned to be 0.5 in this work.

\section{Results and Discussion}

5.1. Compression Tests. The results of compression test for three types of EVA and one type of NBR are shown in Figure 5. The top stress-strain curve is for EVA 55 specimen and the bottom curve is for NBR. As shown, among these four types of resilient materials, the stress-strain curve becomes higher with the increasing of the Shore A hardness. The indicated points of the stress-strain curve were input as tabulated data for the loading curve of Material Type 57. Young's moduli of these four materials were obtained from the linear parts of their curves, and their values are 2.91, 1.41, 0.615, and 0.419 $\mathrm{MPa}$ from high to low. In addition, the densities are 70,77 , and $130 \mathrm{~kg} / \mathrm{m}^{3}$ for EVAs 25,35 , and 55 , respectively, and $83 \mathrm{~kg} / \mathrm{m}^{3}$ for NBR.

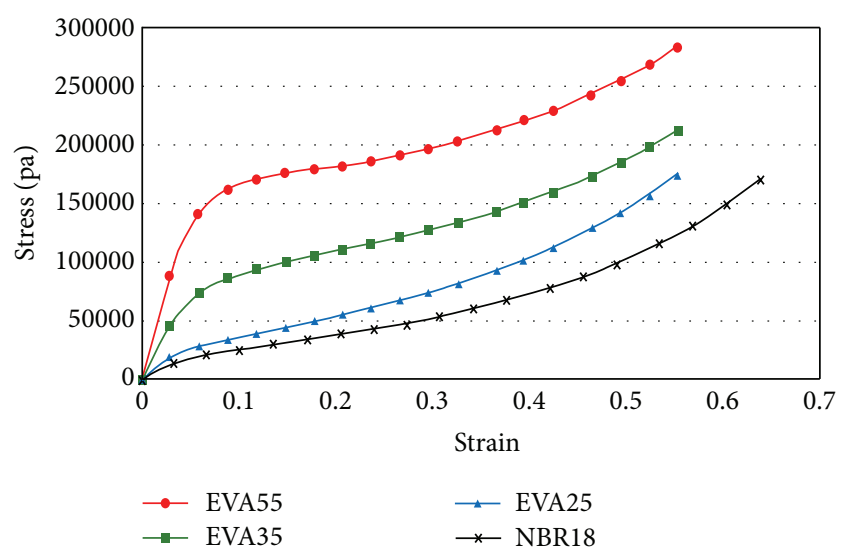

FIGURE 5: Stress-strain curves of resilient materials.

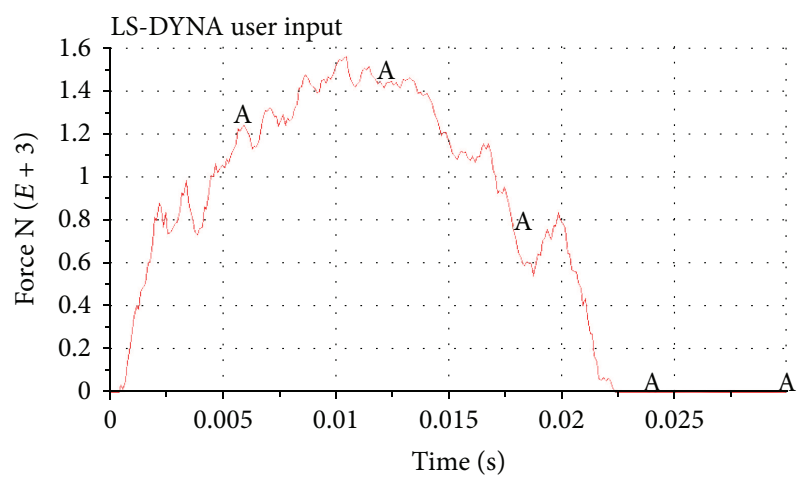

FIGURE 6: Simulated impact force of rubber ball with respect to time.

5.2. Impact Behavior of Rubber Ball. To investigate the impact behavior of rubber ball, only the rubber ball and the RC floor were considered in the simulation model without the tested panel. The simulation results are listed in Table 4 for the Shore A hardness from 40 to 50 . As shown, the variations of the force integration and the impact duration are small, while the maximum impact force has clear change from $1350.5 \mathrm{~N}$ to $1695.9 \mathrm{~N}$. Similarly, the average impact force is varied from $849.6 \mathrm{~N}$ to $1071.8 \mathrm{~N}$, and the average acceleration ranges from 331.6 to $421.2 \mathrm{~m} / \mathrm{s}^{2}$. As compared to the target values listed in Table 2, it is clear that the suitable Shore A hardness should be around 46 to 47 . Since there is no available data for the parameters $A$ and $B$ corresponding to the Shore A hardness from 46 to 47 , linear interpolation is applied to create the corresponding values as listed in Table 5 , and the simulation results are also shown. As compared to the target values, the case with the Shore A hardness of 46.8 has the best agreement and is adopted hereafter. At this case, the maximum impact force is $1558 \mathrm{~N}$, the average impact force is $999 \mathrm{~N}$, and the average acceleration is $392 \mathrm{~m} / \mathrm{s}^{2}$. The waveform of the impact force obtained by the present simulation is shown in Figure 6 .

5.3. Impact Vibration. To obtain reliable results by finite element analysis, different meshes were tested. The acceleration values of Point $A$ as shown in Figure 3 along the vertical direction with respect to the total element number are shown 
TABLE 4: Simulation results of rubber model for Shore A hardness from 40 to 50.

\begin{tabular}{|c|c|c|c|c|c|c|c|}
\hline Shore A hardness & $A$ & $B$ & $Y(\mathrm{~N} \cdot \mathrm{s})$ & $F_{\max }(\mathrm{N})$ & $F_{\text {avg }}(\mathrm{N})$ & $A_{\text {avg }}\left(\mathrm{m} / \mathrm{s}^{2}\right)$ & Impact duration (s) \\
\hline 40 & 0.181 & 0.045 & 22.003 & 1350.5 & 849.586 & 331.602 & 0.0258 \\
\hline 41 & 0.189 & 0.047 & 21.823 & 1499.5 & 856.193 & 334.157 & 0.0254 \\
\hline 42 & 0.198 & 0.050 & 22.015 & 1403.7 & 880.695 & 340.317 & 0.0252 \\
\hline 43 & 0.209 & 0.052 & 22.031 & 1409.0 & 903.083 & 349.137 & 0.0246 \\
\hline 44 & 0.220 & 0.055 & 22.019 & 1452.1 & 936.837 & 366.694 & 0.0234 \\
\hline 45 & 0.232 & 0.058 & 21.998 & 1466.3 & 956.611 & 374.695 & 0.0229 \\
\hline 46 & 0.245 & 0.061 & 22.022 & 1527.4 & 974.545 & 381.938 & 0.0225 \\
\hline 47 & 0.259 & 0.065 & 21.964 & 1534.1 & 1007.673 & 395.141 & 0.0217 \\
\hline 48 & 0.273 & 0.068 & 21.961 & 1595.3 & 1035.665 & 406.381 & 0.0211 \\
\hline 49 & 0.287 & 0.072 & 21.924 & 1619.1 & 1058.957 & 415.757 & 0.0206 \\
\hline 50 & 0.302 & 0.076 & 21.970 & 1695.9 & 1071.826 & 421.160 & 0.0204 \\
\hline
\end{tabular}

in Figure 7 without the resilient material (denoted as null in the figure) and with EVA 55. From these two curves, the acceleration of Point $\mathrm{A}$ is reduced dramatically with the increase of element number. Also, it could be said that the acceleration converges as the total element number is close to 400,000 for both cases. Hence, in this work, about 379,860 elements were used for the case without resilient materials, and about 408180 elements were used for the case with resilient materials. The element size for the rubber ball and the tested panel is $5 \mathrm{~mm}$, and the total element number for RC floor is about 262,500. There are about 28,320 elements for all EVAs and NBR 18.

The maximum upward acceleration of Point A obtained by both the simulation and the measurement is shown in Table 6. Figure 8 shows the predicted and measured vertical acceleration of Point A with respect to time for the case without resilient materials, and those for the cases with EVAs 55, 35, and 25 and NBR 18 are shown in Figures 9, 10, 11, and 12. In the table, the results of five repeated measurements and the average value are presented. When there is no resilient material, there are just solid wood and plywood in the tested panel. The predicted maximum upward acceleration of Point A along vertical direction is $28.15 \mathrm{~g}$, where $\mathrm{g}$ is the gravity acceleration. The measured result is $26.16 \mathrm{~g}$, and there is $7.6 \%$ error between these two values. As the resilient materials are included, the error of the simulation is from $6.9 \%$ to $17 \%$. The largest error occurs at the case of EVA 35, in which the measured result is $10.93 \mathrm{~g}$ and the simulation one is $12.81 \mathrm{~g}$. In addition to the maximum vertical acceleration, Figures 8-12 show the detailed variation of the vertical acceleration of point A with respect to time. As shown, the ranges of the vertical acceleration from the test and the simulation are very close. As for the detailed peaks, they are quite different. The maximum peaks from the simulation always occur at the first stage, while those from the test may be at the first peak or at later peaks. To further improve the simulation results in the future, one possibility is to obtain precise value of the parameters used in the material models. At this stage, the material models used in this work should be able to capture the impact and vibration behavior of the considered materials, and the present simulation should be able to evaluate the insulation effect of the resilient materials. From

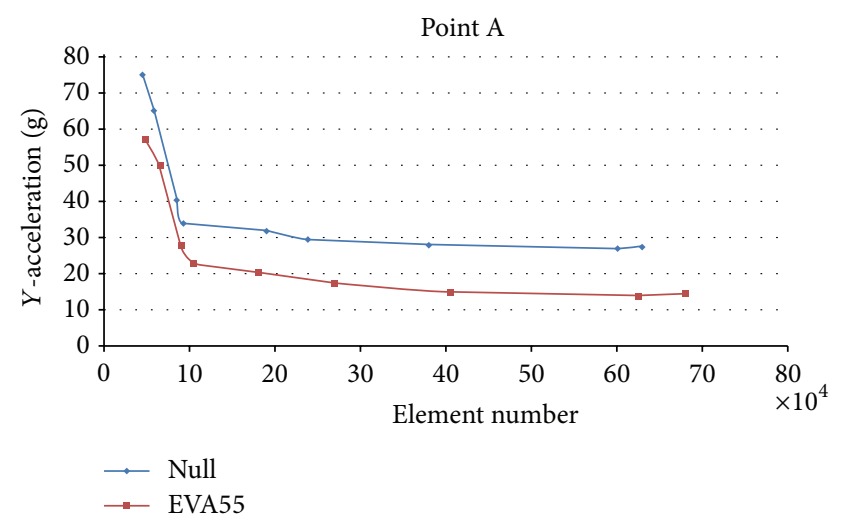

FIGURE 7: Convergence analysis for element number without and with resilient materials.

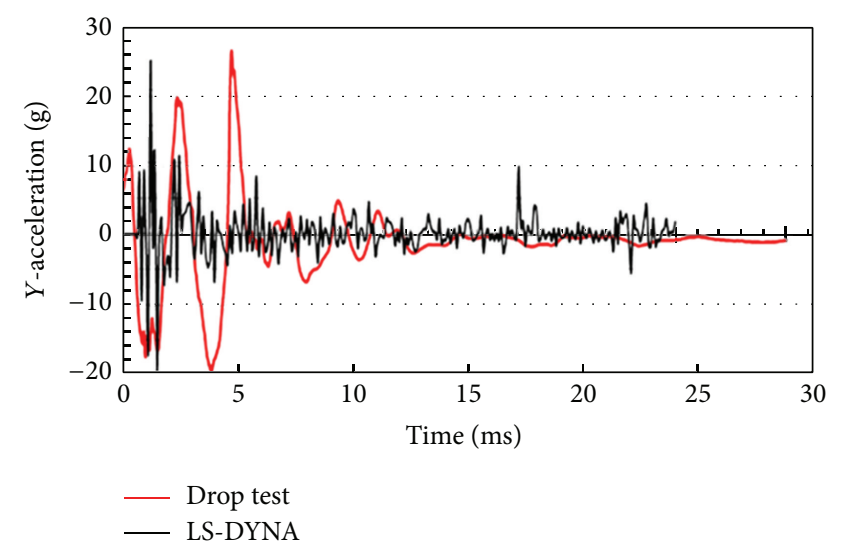

FIGURE 8: Vertical acceleration of point A without resilient materials.

the present results, it is evident that the resilient material could significantly reduce the vibration, and the resilient material with lower Shore A hardness or Young's modulus has better effect. 
TABLE 5: Simulation results of rubber model for Shore A hardness from 46 to 47.

\begin{tabular}{lccccccc}
\hline Shore A hardness & $A$ & $B$ & $Y(\mathrm{~N} \cdot \mathrm{s})$ & $F_{\max }(\mathrm{N})$ & $F_{\text {avg }}(\mathrm{N})$ & $A_{\text {avg }}\left(\mathrm{m} / \mathrm{s}^{2}\right)$ & Impact duration $(\mathrm{s})$ \\
\hline 46.0 & 0.2450 & 0.0610 & 22.022 & 1527.4 & 974.545 & 381.938 & 0.0225 \\
46.1 & 0.2464 & 0.0614 & 22.002 & 1539.4 & 977.863 & 383.251 & 0.0224 \\
46.2 & 0.2478 & 0.0618 & 22.005 & 1523.1 & 982.516 & 385.115 & 0.0223 \\
46.3 & 0.2492 & 0.0622 & 22.007 & 1526.3 & 978.126 & 383.519 & 0.0224 \\
46.4 & 0.2506 & 0.0626 & 21.962 & 1533.2 & 984.678 & 386.061 & 0.0222 \\
46.5 & 0.2520 & 0.0630 & 21.958 & 1546.5 & 989.207 & 387.677 & 0.0221 \\
46.6 & 0.2534 & 0.0634 & 21.977 & 1569.1 & 994.501 & 389.906 & 0.0220 \\
46.7 & 0.2548 & 0.0638 & 21.987 & 1535.7 & 994.743 & 390.007 & 0.0220 \\
46.8 & 0.2562 & 0.0642 & 21.984 & 1558.1 & 999.251 & 391.803 & 0.0219 \\
46.9 & 0.2576 & 0.0646 & 21.996 & 1565.6 & 1004.375 & 393.822 & 0.0218 \\
47.0 & 0.2590 & 0.0650 & 21.964 & 1534.1 & 1007.673 & 395.141 & 0.0217 \\
\hline
\end{tabular}

TABLE 6: Measured and simulated maximum acceleration under resilient materials.

\begin{tabular}{lccccccc}
\hline Tested panel & Test 1 $(\mathrm{g})$ & Test 2 $(\mathrm{g})$ & Test 3 $(\mathrm{g})$ & Test 4 $(\mathrm{g})$ & Test 5 $(\mathrm{g})$ & Average $(\mathrm{g})$ & Simulation $(\mathrm{g})$ \\
\hline No resilient & 26.11 & 26.47 & 26.38 & 25.65 & 26.17 & 26.16 & $28.15(7.6 \%)$ \\
With NBR 18 & 7.57 & 7.75 & 7.59 & 7.48 & 7.39 & 7.56 & $8.78(16.1 \%)$ \\
With EVA 25 & 10.33 & 10.07 & 9.41 & 8.73 & 10.28 & 9.76 & $10.43(6.9 \%)$ \\
With EVA 35 & 10.41 & 9.20 & 11.93 & 9.74 & 13.25 & 10.93 & $12.81(17.2 \%)$ \\
With EVA 55 & 17.28 & 16.85 & 14.64 & 17.84 & 16.04 & 16.53 & $14.86(-10.1 \%)$ \\
\hline
\end{tabular}

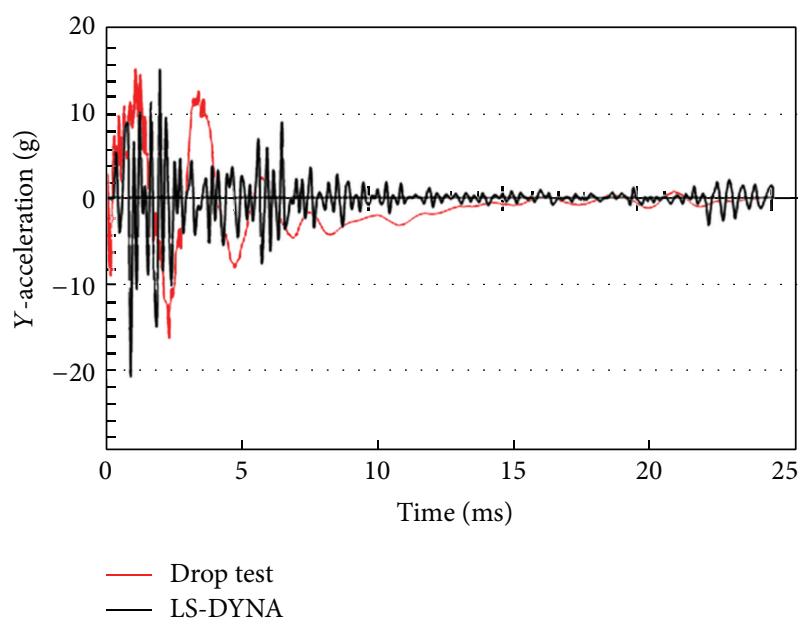

FIGURE 9: Vertical acceleration of point A with resilient material EVA 55.

\section{Conclusions}

The present work uses an explicit finite element code to model the impact behavior of the rubber ball and to predict the floor impact vibration under resilient materials. The results indicate that the hyperviscoelastic rubber model could precisely simulate the impact force of rubber balls, and its two parameters could be properly chosen according to the desired impact force. Upon this result, the impact vibration of the tested panel consisting of solid wood plate, plywood

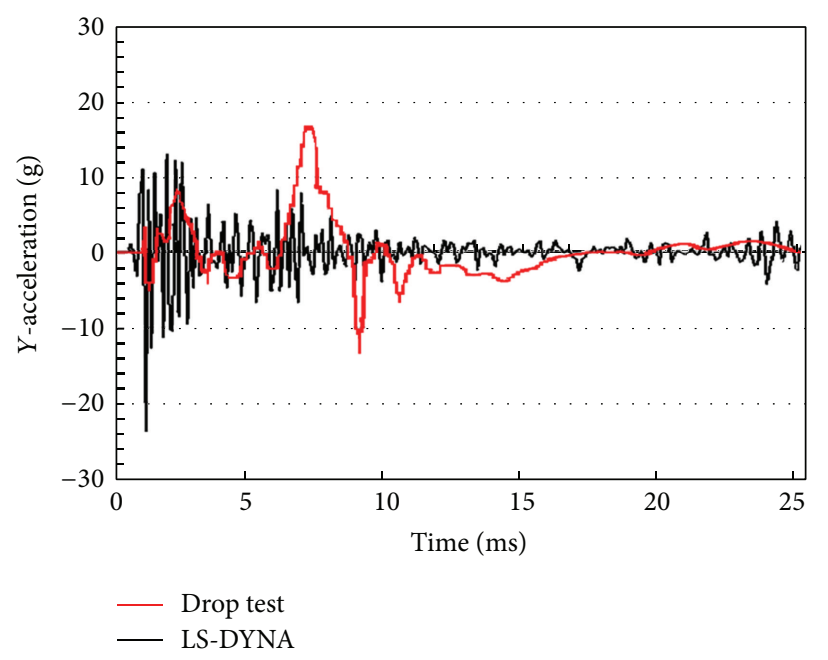

FIgURE 10: Vertical acceleration of point A with resilient material EVA 35.

plate, and resilient materials could be predicted. Then, the insulation effect of resilient materials could be evaluated. As compared to the experimental results, the present model could capture the impact and vibration behavior of the considered materials and reasonably evaluate the insulation effect of resilient materials. In addition, the resilient material with lower Shore A hardness could reduce more the impact vibration. 


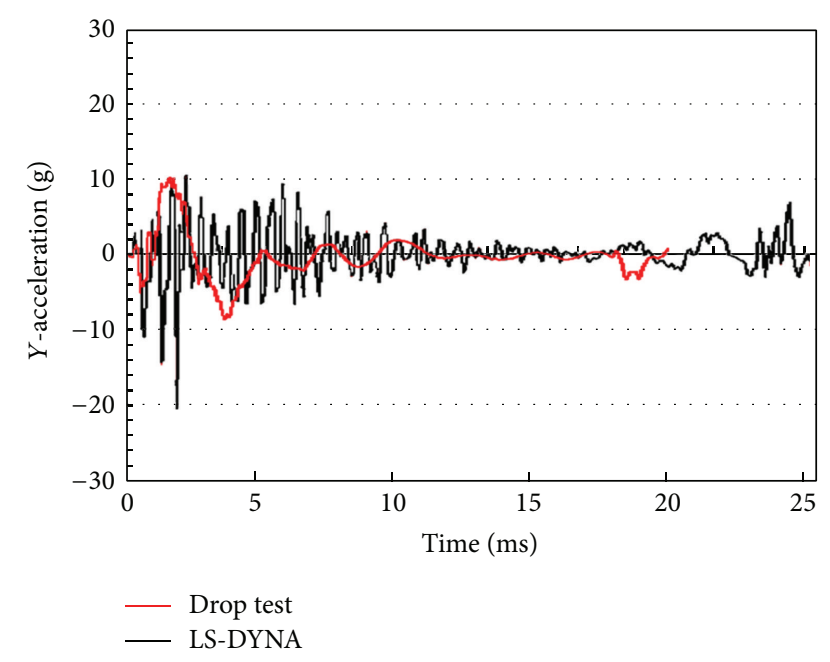

FIGURE 11: Vertical acceleration of point A with resilient material EVA 25.

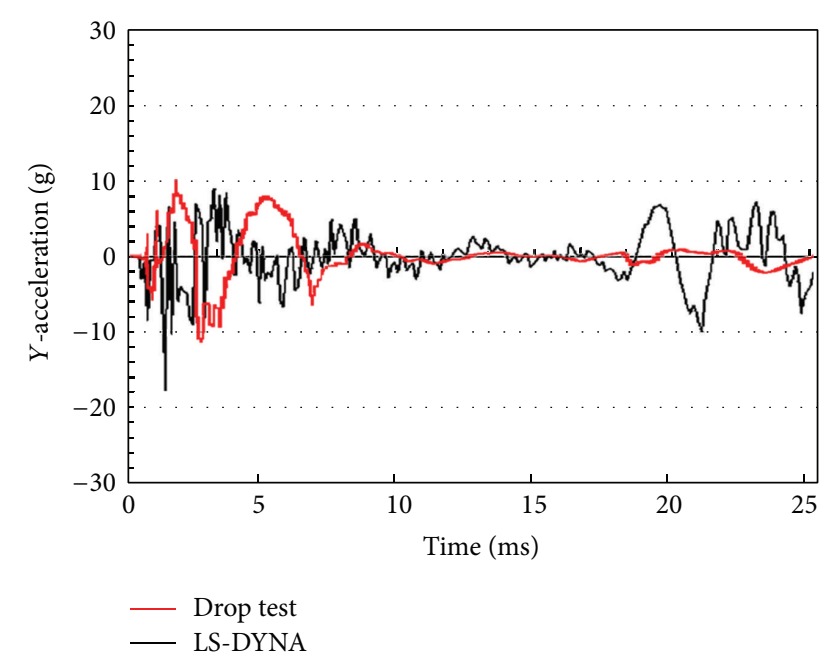

FIGURE 12: Vertical acceleration of point A with resilient material NBR 18.

\section{Conflict of Interests}

The authors declare that there is no conflict of interests regarding the publication of this paper.

\section{Acknowledgments}

The financial support from National Science Council, Taiwan, and Boid Construction Co. through NSC99-2622-E-224010-CC3 and NSC 100-2622-E-224-014-CC3 is gratefully acknowledged.

\section{References}

[1] T. Pritz, "Dynamic Young's modulus and loss factor of plastic foams for impact sound isolation," Journal of Sound and Vibration, vol. 178, no. 3, pp. 315-322, 1994.
[2] I. L. Ver, "Impact noise isolation of composite floors," The Journal of the Acoustical Society of America, vol. 50, no. 4, pp. 1043-1050, 1971.

[3] L. Cremer, M. Heckl, and E. Ungar, Structure-Borne Sound, Springer, Berlin, Germany, 1988.

[4] W. Shi, C. Johansson, and U. Sundbäck, "An investigation of the characteristics of impact sound sources for impact sound insulation measurement," Applied Acoustics, vol. 51, no. 1, pp. 85-108, 1997.

[5] S. Huang, K. Chen, and R. Lai, "Development of standardized impact sources for laboratory measurement of sound transmission through lightweight walls," Applied Acoustics, vol. 58, no. 3, pp. 333-349, 1999.

[6] J. Y. Jeon and S. Sato, "Annoyance caused by heavyweight floor impact sounds in relation to the autocorrelation function and sound quality metrics," Journal of Sound and Vibration, vol. 311, no. 3-5, pp. 767-785, 2008.

[7] S. C. Chung, Y. S. Tsay, C. M. Chiang, R. P. Lai, F. M. Lin, and H. Y. Tsai, "Study on the applicability of using rubber ball for standardized heavy/soft floor impact sources in Taiwan," Journal of Architecture, vol. 72, pp. 57-71, 2010.

[8] J. Y. Jeon, J. K. Ryu, H. Jeong, and H. Tachibana, "Review of the impact ball in evaluating floor impact sound," Acta Acustica united with Acustica, vol. 92, no. 5, pp. 777-786, 2006.

[9] B. Park, J. Y. Jeon, and J. Park, "Force generation characteristics of standard heavyweight impact sources used in the sound generation of building floors," Journal of the Acoustical Society of America, vol. 128, no. 6, pp. 3507-3512, 2010.

[10] P. C. Tzeng, C. M. Chiang, S. C. Chung, and W. C. Hsieh, "A prediction model for impact sound insulation of floor coverings by finite element method," Journal of Architecture, vol. 59, pp. 113-125, 2007.

[11] M. A. Stewart and R. J. M. Craik, "Impact sound transmission through a floating floor on a concrete slab," Applied Acoustics, vol. 59, no. 4, pp. 353-372, 2000.

[12] A. Tadeu, A. Pereira, L. Godinho, and J. António, "Prediction of airborne sound and impact sound insulation provided by single and multilayer systems using analytical expressions," Applied Acoustics, vol. 68, no. 1, pp. 17-42, 2007.

[13] C. M. Chiang, P. C. Tzeng, S. C. Chung, C. M. Chung, and C. $\mathrm{Y}$. Su, "A FEM prediction model for influence of the well-mixed ceiling upon impact sound insulation," Journal of Architecture, vol. 66, pp. 189-206, 2008.

[14] C. Y. Kuo, Experimental investigation on floor impact sound insulation with floor coverings construction-taking impact ball as examples [M.S. thesis], National Yunlin University of Science and Technology, 2007.

[15] I. M. Rushforth, K. V. Horoshenkov, M. Miraftab, and M. J. Swift, "Impact sound insulation and viscoelastic properties of underlay manufactured from recycled carpet waste," Applied Acoustics, vol. 66, no. 6, pp. 731-749, 2005.

[16] K. W. Kim, G. C. Jeong, K. S. Yang, and J. Y. Sohn, "Correlation between dynamic stiffness of resilient materials and heavyweight impact sound reduction level," Building and Environment, vol. 44, no. 8, pp. 1589-1600, 2009.

[17] A. Neves E Sousa and B. M. Gibbs, "Low frequency impact sound transmission in dwellings through homogeneous concrete floors and floating floors," Applied Acoustics, vol. 72, no. 4, pp. 177-189, 2011.

[18] C. I. Lu, Predicting the influence of the access floor concerning impact sound insulation using FEM [M.S. thesis], National Cheng-Kung University, Tainan, Taiwan, 2007. 
[19] P. L. Chen, Predicting the influence of the double rooms with light steel-gauge partition concerning floor impact sound using FEM [M.S. thesis], National Cheng-Kung University, 2008.

[20] Japanese Industrial Standard JISA 1418, Part 2: acousticsmeasurement of floor impact sound insulation of buildings. Part 2: method using standard heavy impact sources, 2000.

[21] ISO 140-11, "Acoustics-measurement of sound insulation in buildings and of building element - Part 11: laboratory measurements of the reduction of transmitted impact sound by floor coverings on lightweight reference floors," 2005.

[22] LS-DYNA User's Manual, 2007.

[23] S. F. Hwang, C. W. Chen, S. C. Chung, and Y. S. Tsay, "Impact simulation of rubber ball for standardized heavy weight floor impact sources," Advanced Science Letters, vol. 14, no. 1, pp. 299303, 2012.

[24] 2011, http://forum.simwe.com/. 

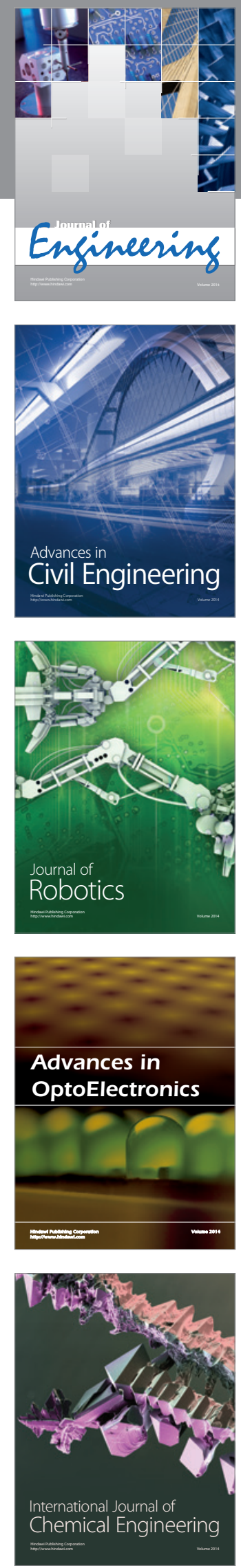

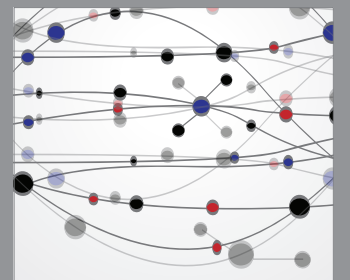

The Scientific World Journal
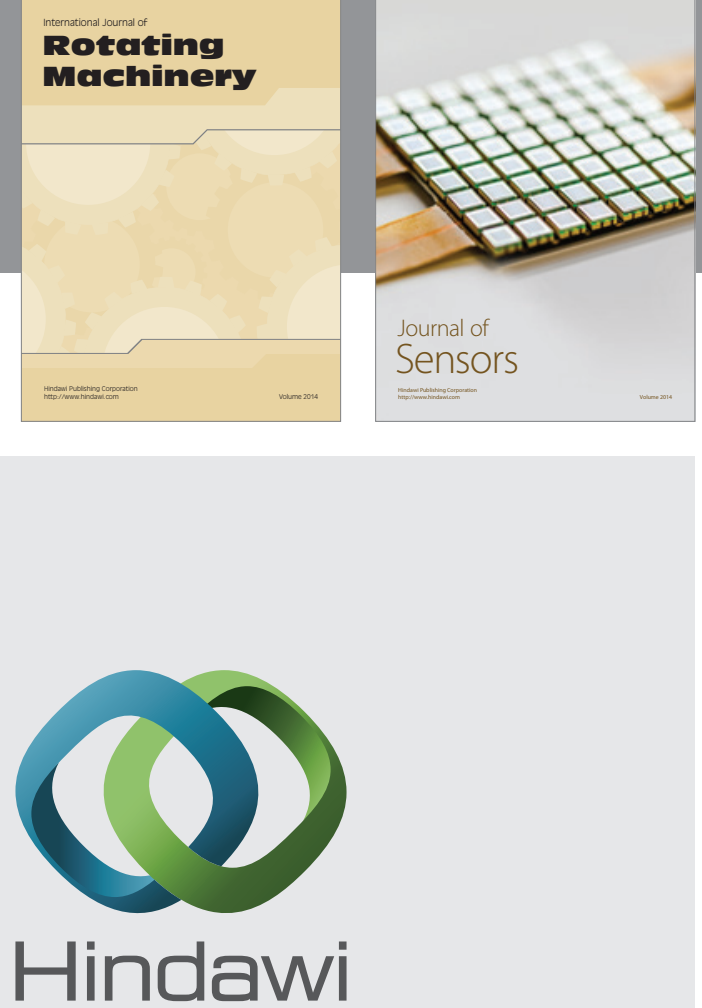

Submit your manuscripts at http://www.hindawi.com
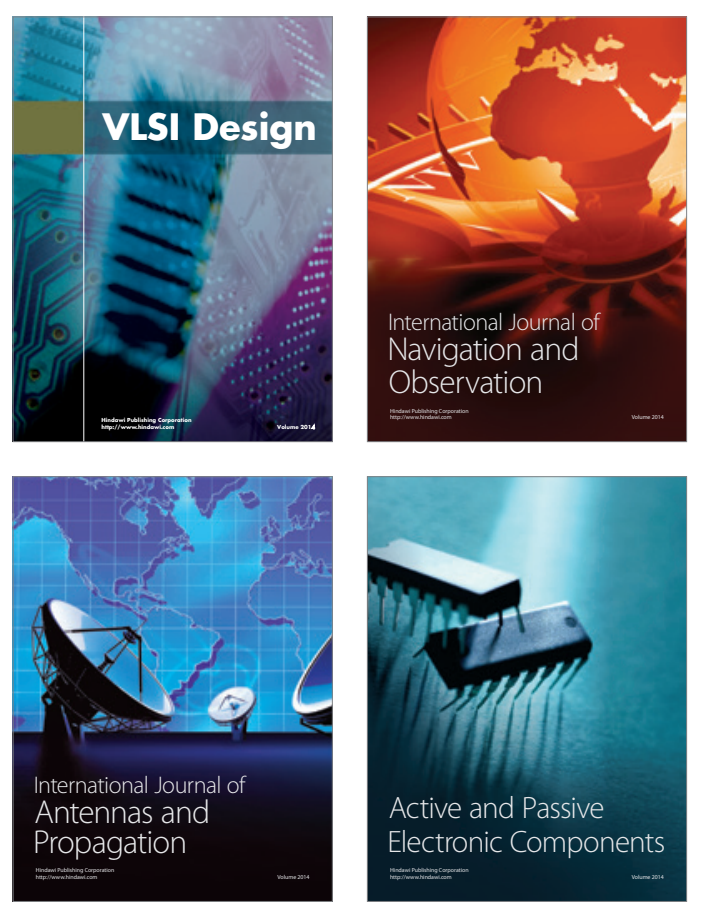
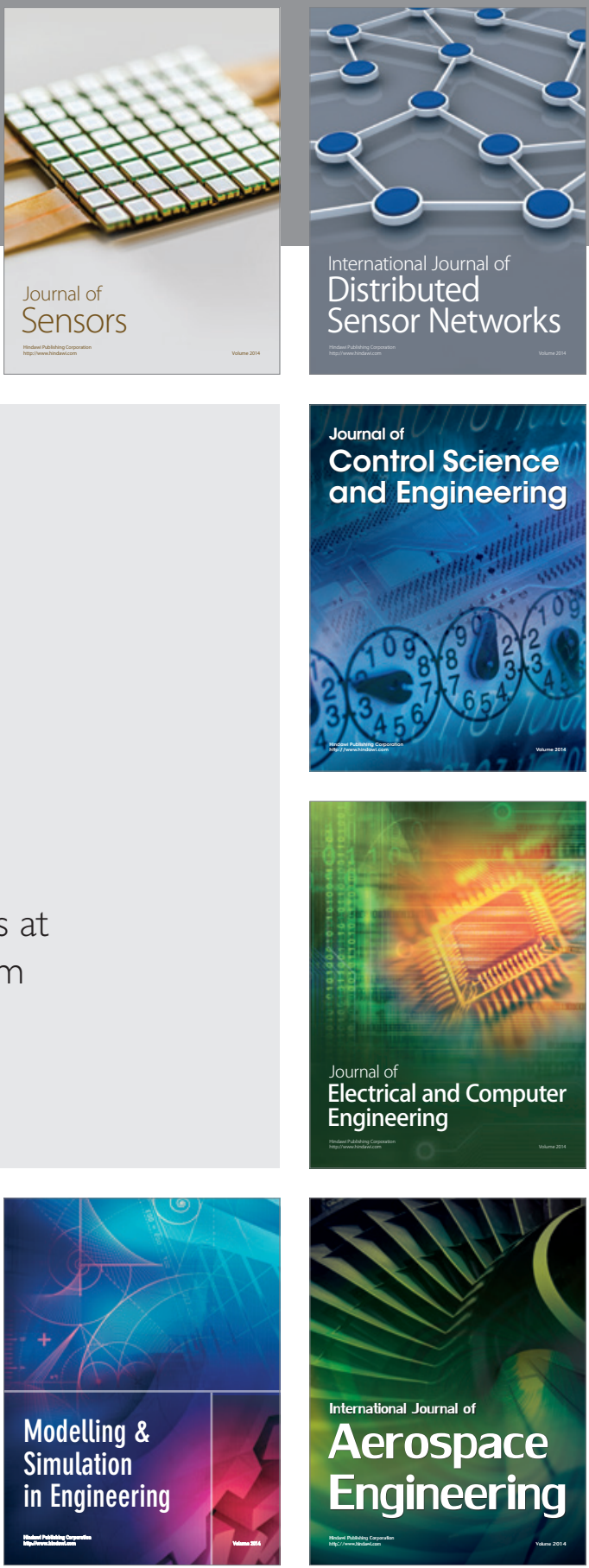

Journal of

Control Science

and Engineering
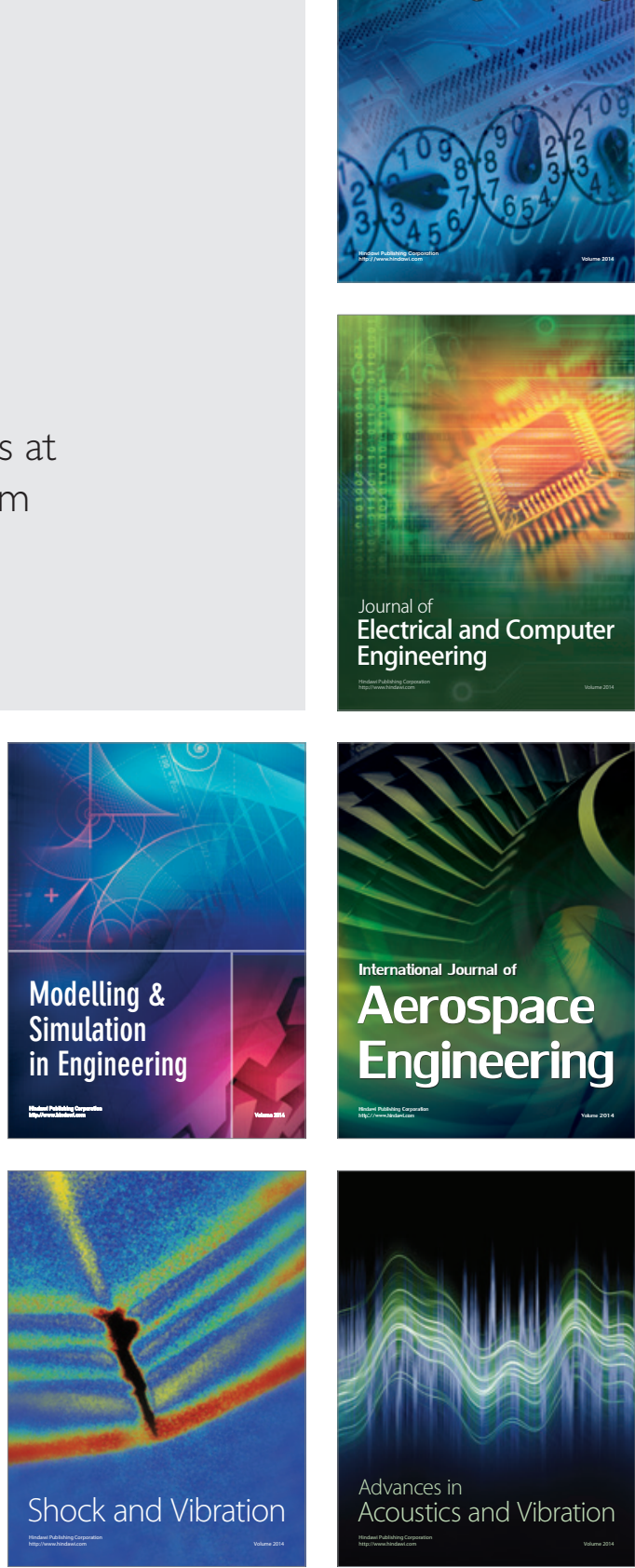